\title{
Attitude of Students towards the Use of Library Facilities: A Case Study
}

\author{
Dr. Jamilah Alokluk* \\ Taibah University, Madinah, Saudi Arabia
}

\begin{abstract}
*Corresponding Author: Dr. Jamilah Alokluk, Taibah University, Madinah, Saudi Arabia
\end{abstract}
\begin{abstract}
Information is the most powerful tool in learning endeavours. Libraries are collections of information in organised ways to make it accessible to the target audience. The main challenge, however, is the underutilisation of library resources by students in many learning institutions. The purpose of this study was to determine the attitude of students towards the use of library facilities. The study involved 66 participants out of which 60 were students in different years of study, whereas 6 were library staff at Newcastle University, United Kingdom. Closed-ended questionnaires were administered to the students while structured face-to-face interviews were used to collect information from the library workers. The university recorded high rates of library usage of $92 \%$. About $49 \%$ of students used the library twice a week. The purposes of visiting the library in order of priority were finding space to read personal study notes, using the internet, using library materials within the building, reading newspapers, meeting friends and using printing and photocopy services. There was student dissatisfaction regarding the availability of comfortable space to study in the library. There was a lack of awareness about the inter-library borrowing facility, which was highly underutilised in the institution. Overall the study concluded that the students' attitude towards the use of library facilities was positive. However, there was a need to implement the proposed recommendations to increase the use of library services.
\end{abstract}

Keywords: Attitude, Information, Learning resources, Library, Service utilization.

\section{INTRODUCTION}

Academic libraries are valuable facilities in any learning institution because they provide an environment for students to advance their knowledge. Libraries are also valuable to teaching staff (faculty) because they provide an enabling research environment (Saunders 2015). Therefore, they are considered the "heart" of a learning institution. Libraries must be structured to support these learning needs. Nonetheless, an interesting observation is that there is an underutilisation of the library facilities in most institutions (Chen 2015; Ibrahim \& Sakiyo 2015), which is counterproductive to the goals and objectives of the library department with regard to enhancing access to information. Several hypotheses have been suggested to explain the irregular patterns of library resource usage in learning institutions. However, these suggestions are not one-size-fits-all solutions for library use issues in different settings and contexts. Given the integral role of universities in the higher education system, educational institutions should ensure that library services are optimal for its student and faculty population. This feat can only be achieved by understanding the perceptions and needs of students regarding the library. This paper examines the attitudes of university students towards the use of library services.

\subsection{Statement of the Problem}

The library is an important learning resource in any academic institution. Recent trends and advancements in technology have led to the modernisation of library services, including the development of vast online databases with a wealth of information to guide learning and research (Delaney \& Bates 2015). However, despite these developments, the utilization of library services is not optimal in most learning institutions, which limits the realization of educational benefits that accrue from library use. There is a scarcity of information regarding the attitudes and perceptions of library services among university students. Information providers need to comprehend the specific needs of prospective library users to meet them. Without this knowledge, it is impossible to optimise the services provided by the library for the benefit of institutional academic programs. Therefore, this study strives to unravel the attitudes of university students towards library services. 


\subsection{Objectives of the Study}

The overall objective of this study is to determine the attitudes of students towards the use of library services. Three specific objectives will be pursued to contribute towards the attainment of the overall objective.

- To determine the current rate of utilization of library services.

- To determine student satisfaction with library services.

- To identify barriers against the utilization of library services.

- To identify potential solutions to improve the utilization of library services.

\subsection{Research Questions}

The following research questions correlate with the specific objectives of the study.

- What is the current rate of library service utilization among university students?

- Are students satisfied with the current library services?

- What are the barriers against the use of library facilities by university students?

- What can be done to eliminate these barriers?

\subsection{Scope of the Study}

This study will examine the attitudes of students regarding the use of library facilities in an institution of higher learning using quantitative and qualitative means. The key limitation of the study is the availability of financial resources. Therefore, it will not be possible to collect data from many participants to improve the robustness of the study.

\subsection{Research Focus}

Trends in information literacy have revolutionized library services in learning institutions (Brabazon 2016). As a result, attracting and maintaining the attention of the contemporary student is no mean feat for academic libraries. Furthermore, students often face time constraints due to numerous activities that demand their time, including classes, assignments, sports and social activities (Rettig \& $\mathrm{Hu}$ 2016).Planning and implementing library awareness and information literacy programs for new and ongoing students is challenging for librarians. The purpose of this work is to examine the attitudes of students towards the use of library facilities. Students undergo library orientation in the first semester of their first academic year, which is meant to provide them with an overview of the library and the range of services that can be accessed. However, details regarding how to access specific information are attained in the course of learning as faculty recommends learning materials for different subjects. Understanding the perceptions and information needs of students will guide the development of effective strategies to attain information literacy and optimal use of the library facility. Additionally, such a move will also enable the creation of user-centred services.

\section{RESEARCH METHOD}

The study aimed to investigate students' perceptions of the role of the library in support of their studies. This section provides the research approaches and design adopted for the study. It also describes the study population, sampling procedures, data collection and analysis as well as ethical considerations for the study.

\subsection{Research Approach}

Research approaches fall under three main categories of qualitative, quantitative and mixed methods. A researcher's objectives determine the research approach that is chosen. For example, quantitative approaches are necessary when a researcher intends to measure and compare variables. The rationale for this choice is that quantitative approaches yield numerical data that can be manipulated using mathematical and statistical formulae to draw meaningful conclusions about the study variables. Additionally, quantitative studies permit researchers to collect data from large samples, hence enhancing the generalisability of the findings to the population (Blackstone 2018). The major shortcoming of quantitative research is that investigators cannot comprehend the context of the 
findings as well as additional factors that influence the observations that cannot be captured quantitatively (Taylor, Bogdan \& DeVault 2015). Furthermore, quantitative studies are usually expensive, often requiring a lot of financial resources to execute.

In contrast, the qualitative research approach strives to unravel and develop an in-depth understanding of how and why certain phenomena occur (Taylor, Bogdan \& DeVault 2015). Features such as predominant themes, people's behaviour and patterns of events can be captured in a qualitative approach. Therefore, a researcher can attach meaning to observed phenomena. Qualitative data can be obtained through interviews where the investigator has direct contact with correspondents or through observations where the researcher can collect data without interacting directly with the study participants. Another advantage of qualitative studies is that it is cheaper than quantitative inquiries because it does not need very large samples. Furthermore, the investigator is not bound by a specific theoretical framework and is free to steer the data collection in the desired direction. However, there may be study biases due to prejudiced interpretations of data by the researcher. The analysis of qualitative data can be complicated by diverse coding systems. Consequently, findings from these inquiries cannot be reproduced (Taylor, Bogdan \& DeVault 2015).

Mixed-methods studies combine quantitative and qualitative research approaches. The investigator approaches the study question from quantitative and qualitative perspectives. Therefore, such an approach bears the benefits of both methods. A wealth of information is generated because the quantitative bit generates numerical data backed by statistical inferences, whereas the qualitative aspect explains the observations. Consequently, one can gain a better understanding of the phenomenon being investigated. For this study, quantitative and qualitative research approaches were employed. Quantitative data were collected from a representative sample and used to generalise the observations to the entire population. In contrast, qualitative findings were used to provide an in-depth understanding of the observations (students' attitudes towards library use from the standpoint of library staff) as well as providing further support.

\subsection{Research Design}

A case study research design was followed for this study. Creswell (2014) reports that a case study is a qualitative design where the investigator delves deeply into an activity, event or process. Case studies are empirical inquiries in social studies that look into an issue in its real-life context. Consequently, a researcher gets to experience what it feels like to be in a given situation when conducting a case study. Case studies allow a researcher to concentrate on a few units thus providing detailed information. Therefore, they involve descriptive evaluations of phenomena, even though the resultant claims or hypotheses can be tested further through additional studies. Quantitative evidence from multiple sources can be used to build up a case study (Taylor, Bogdan \& DeVault 2015).

The advantages of a case study include the ability to collect detailed information (rich data) that would not otherwise be possible through other research designs (Ulriksen \& Dadalauri 2016). Scientific experiments can still be done as part of a case study. One case can provide discernment of events that are common in the group from which the case was drawn. The main criticism against case studies is that the ensuing data cannot be generalised to the entire population. It is also difficult to infer causality in case study investigations. Case studies often involve one experimenter collecting data, which can lead to bias. This problem was prevented in the study by having each step of the data collection and analysis process appraised by an independent party.

\subsection{Study Population}

The study population included approximately 3000 university students as well as library staff in a learning institution. The student population consists of students at various levels of study (years 1 to 4). Library staff members were included in the study because they were tasked with providing library services to students. Therefore, they were likely to provide objective data regarding the use of library facilities by the students.

\subsection{Sampling}

Sampling can be defined as the process of selecting representatives from the study population for the analysis of a phenomenon. A total of 60 students and library staff were sampled for the study. Participants in each group were selected differently. To obtain a representative sample of the target population of students two probability sampling methods were adopted, which were stratified random 
sampling and purposive sampling. Stratified random sampling was used to select students to take part in the study. In this approach, the first step involved dividing the target population into strata, which in this case were the years of study. The next step involved the random recruitment of participants from each stratum. Stratified random sampling is relevant in instances where cases in the population belong to different strata to ensure that all sections are equally represented (Sharma 2017). The students were in various levels of study. Therefore, it was necessary to ensure the participation of learners at each level. This way, sampling bias was avoided by giving all participants an equal chance to take part in the investigation. Purposive sampling was used to include library staff in the study. The library staff comprised six members who were all recruited to take part in the study due to the small number.

\subsection{Data Collection}

A questionnaire was used to collect quantitative data from students. A questionnaire can be described as a set of carefully selected questions whose answers contribute to a specified goal (Bryman 2016). Questionnaires are data collection tools in quantitative and qualitative studies where respondents are expected to answer standardised questions related to the research topic. Two types of questions can be used in questionnaires: closed and open-ended questions. This study used closed-ended questions where the participants were restricted to specific answers formulated by the investigator. The main advantages of closed-ended questions are that they are easy to answer and take a shorter time than open-ended questions. Questionnaires were chosen because they are relatively cheap and do not require a lot of time from participants (Patten 2016). Given that the main respondents are students who have busy schedules with activities such as class, assignments and personal study, it was important to encourage their participation by taking up as little time as possible. Another advantage of questionnaires is they are anonymous and encourage the freedom of expression without fear of victimisation.

The questionnaire consisted of two sections with different subject matters. Section A included demographic data and other general characteristics of the study population, whereas the questions in section $\mathrm{B}$ addressed the students 'perceptions of the library. Appendix $\mathrm{C}$ indicates the specific information that was included in the questionnaire. The questionnaires were administered on 4 separate dates.

Qualitative data were collected through structured interviews. An interview is a data collection tool that enables a researcher to gather facts about a phenomenon using preformulated questions in an interactive dialogue. Face-to-face exchanges during interviews enable a researcher to gauge the mood and feelings of the participant (Opsal et al. 2016). Additionally, interviews obtain real-time feedback thus leading to high response rates. It is possible to record the respondent's words for future reference. Ambiguities can be clarified during the interview process, thereby ensuring that accurate answers are provided. The researcher can also follow up on incomplete answers. The effects of external influence are minimised during interviews. However, interviews can be costly due to the resources needed to record, transcribe and analyse data. They are also time-consuming. Using different interviewers can lead to discrepancies in the understanding and transcription of the ensuing data (Bryman 2016). The last problem was avoided by using only one interviewer.

Structured face-to-face interviews were appropriate because they avoided deviations from the subject and minimised misunderstandings based on words or phrases used in the schedule (Shapka et al. 2016). Structured interviews involve asking a prearranged set of questions in the same order and exact wording as detailed in the interview schedule (Vadi et al. 2016). A total of five questions were developed to address various aspects regarding library use by students. For instance, the current utilization of library services, barriers as well as facilitators of library use among students. Each interview lasted approximately 20 minutes. Appendix Dprovides a copy of the interview schedule.

\subsection{Ethical Considerations}

Studies involving human subjects need to uphold ethical standards in all steps. The ethical principles of non-maleficence, beneficence and autonomy were considered (Artal \& Rubenfeld 2017). The study did not involve performing any activities that would result in physical or mental harm to the participants, which was in line with the principle of non-maleficence (do no harm). The findings of the study were meant to enhance student's learning with regard to the use of library resources, which adhered to the principle of beneficence.

The ethical principle of autonomy refers to the demonstration of a person's legal and mental ability to comprehend and make an informed decision (Hammersley 2015). It also involves researching in a 
manner that guarantees the dignity of the participants. This principle is related to issues of informed consent, privacy and confidentiality (Williams \& Pigeot 2017). Prospective respondents were invited to participate in the study and briefed about the nature of the investigation (Appendix A). They were also informed that participation in the study was voluntary and that they were free to leave the study on their own volition. They were also assured that their privacy and confidentiality would be upheld before being asked to sign an informed consent form indicating their agreement to participate in the inquiry (Appendix B). The researcher obtained ethical clearance from the learning institution before proceeding with the study.

\subsection{Data Analysis}

Thematic analysis was used to analyse qualitative data, whereas descriptive statistics were applied to the quantitative data. Thematic analysis is a flexible and useful research tool that provides an in-depth, detailed account of observations that would otherwise be unavailable through quantitative means alone (Javadi \& Zarea 2016). Conversely, descriptive statistics entails summarising data through means, modes and median values, which ease the making of conclusions (Pyrczak 2016). Raw data were recorded in an Excel spreadsheet for further analysis. Deductions were made by further categorising the responses into three main groups. For example, findings on 'strongly agree' and 'agree' were combined to mean 'agreeing with the statement', whereas 'strongly disagree' and 'disagree' were combined to mean 'disagreeing with the statement'. Quantitative data from questionnaires were substantiated by qualitative information that was collected through interviews.

\section{FINDINGS AND DISCUSSIONS}

Of the 60 students that took part in the study, 35 (58\%) were female while 25 were male (42\%) (Figure 1a). About 53\% of the participants were between the ages of 21 to 25 . Only $2 \%$ was 36 years or older (Figure 1b). Students of all study years were selected. Figure 1c shows the distribution of the students based on their years of study. The rate of library use was high with $92 \%$ of students admitting that they used the library (Figure 2). The frequency of library use also varied among the students. 49\% of students used the library on a weekly basis while $16 \%$ used it twice a week. Another $16 \%$ used it every fortnight, whereas $11 \%$ used it once a month (Figure 3 ).

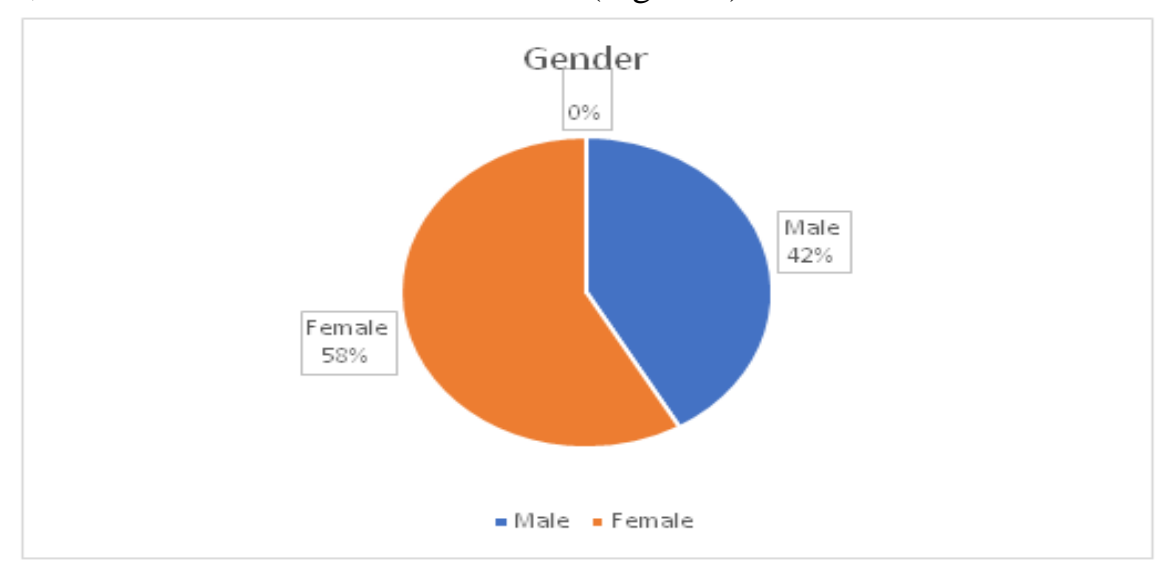

Figure1a: Gender of the participants.

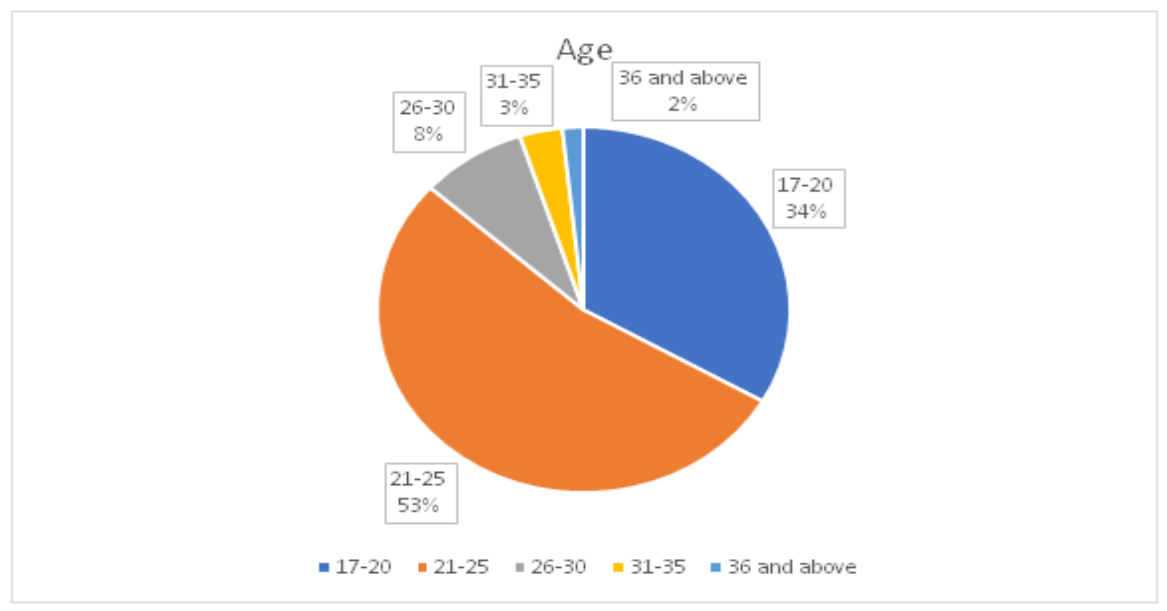

Figure1b: Age of the participants. 


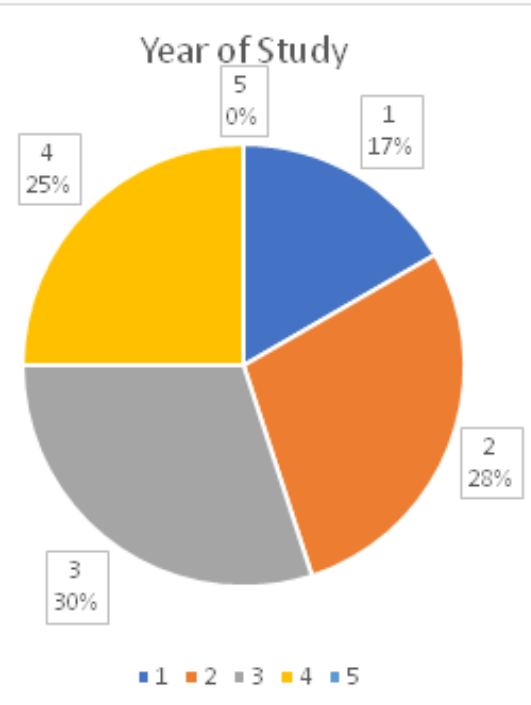

Figure1c: The year of study of the participants.

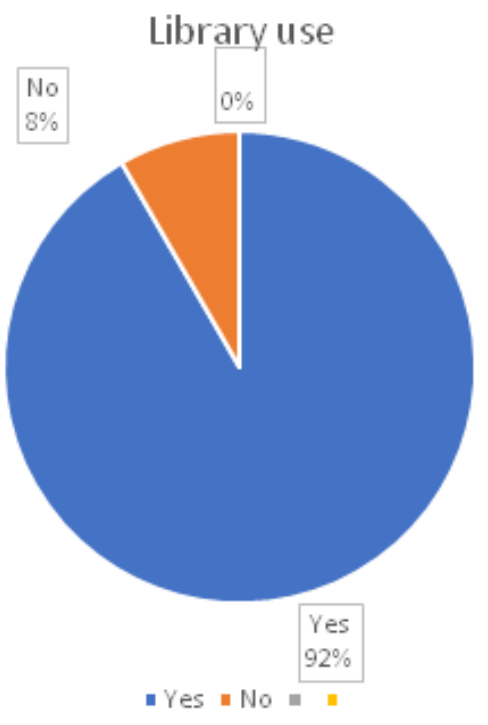

Figure2: Library use among students.

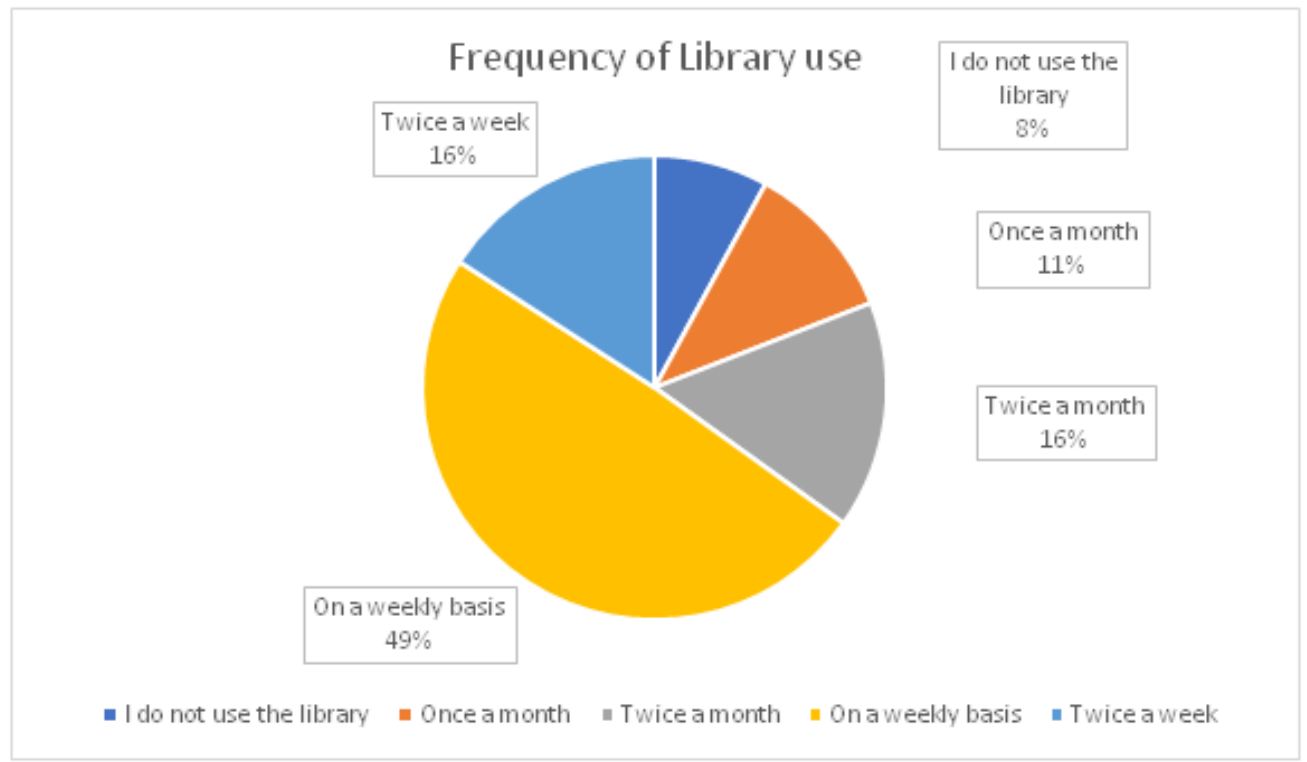

Figure3: Frequency of library use. 


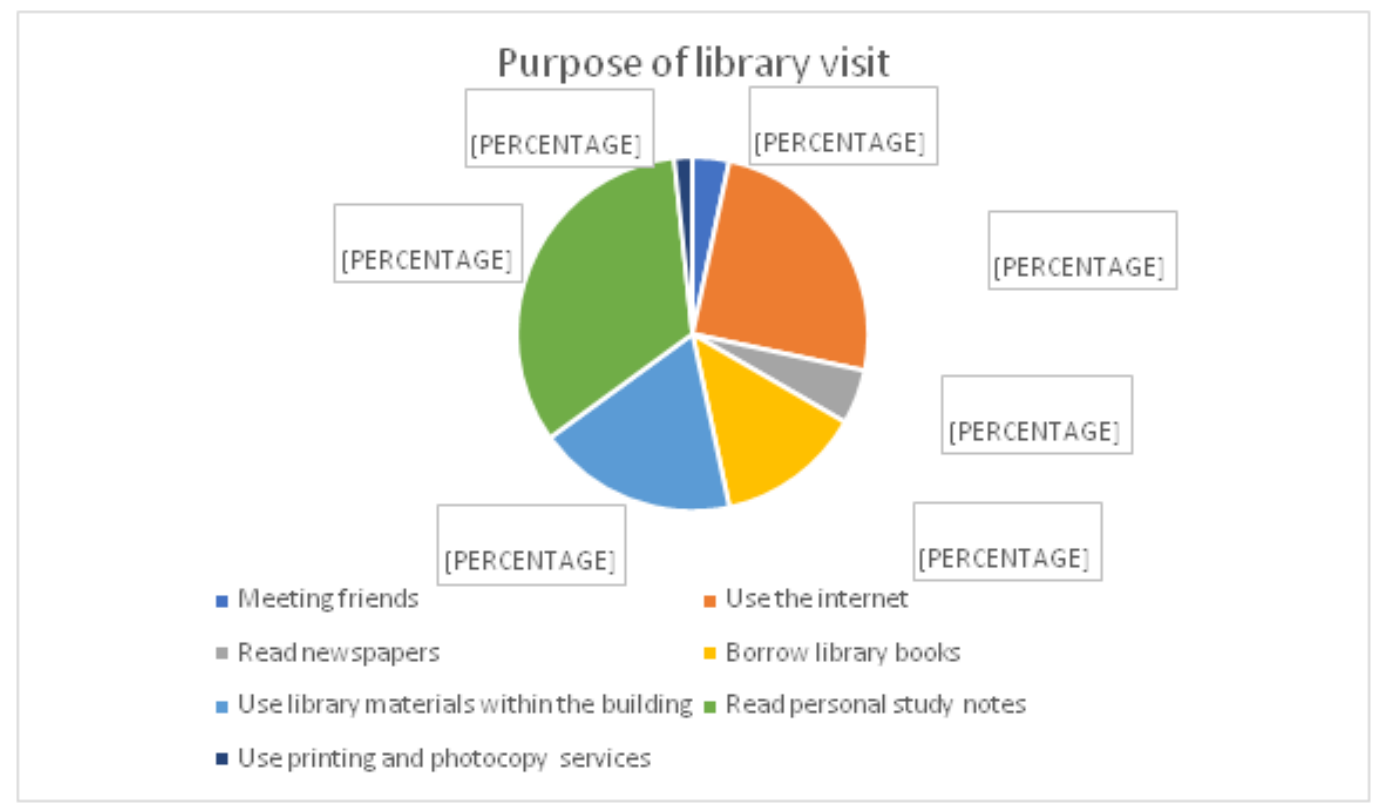

Figure4: Purpose of library visit

The students visited the library for different purposes. The outcomes showed that $34 \%$ went to use the library as a space to read their study materials while $25 \%$ went to use internet services. About $18 \%$ went to use library materials such as books and periodicals within the library while $13 \%$ borrowed books for use away from the library. A fraction of the students (5\%) went to the library to read newspapers, $3 \%$ used it as a meeting point for their friends while only $2 \%$ used the printing and photocopy services offered at the library (Figure 4).

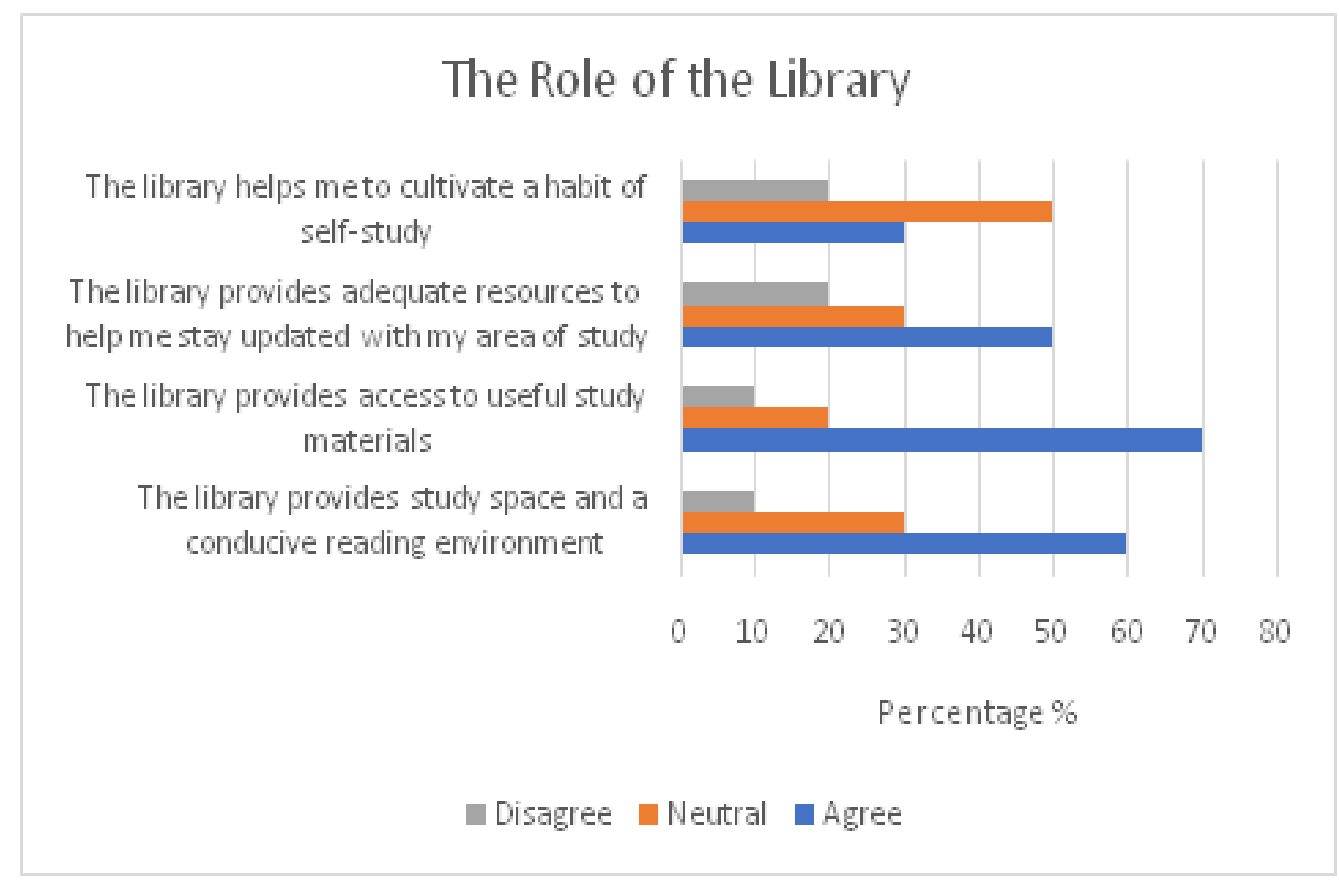

Figure5: The role of the library.

Regarding the role of the library, there was agreement that the library provided adequate and current resources to help students to stay up-to-date with their areas of study. It was also agreed that the library provided access to useful study material as well as a conducive reading environment. However, about $50 \%$ of the participants were neutral about the role of the library in helping them to develop self-study habits (Figure 5).

Students' perceptions about the role of the library also varied. Most (80\%) agreed that it was a useful place for students and that it should be visited as frequently as possible while $60 \%$ saw it as a place to widen their scope of knowledge. Only 5\% saw it as a place to socialise (Figure 6). 


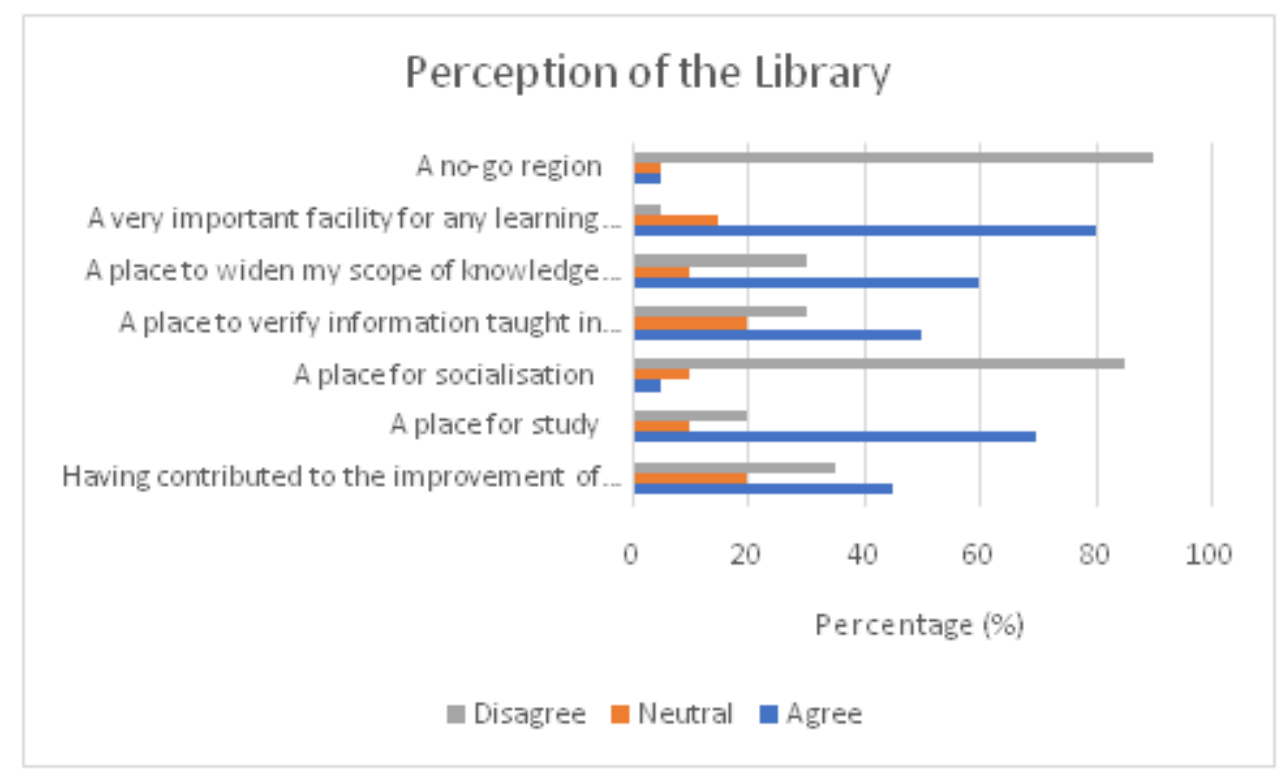

Figure 6: Students' perception of the library.

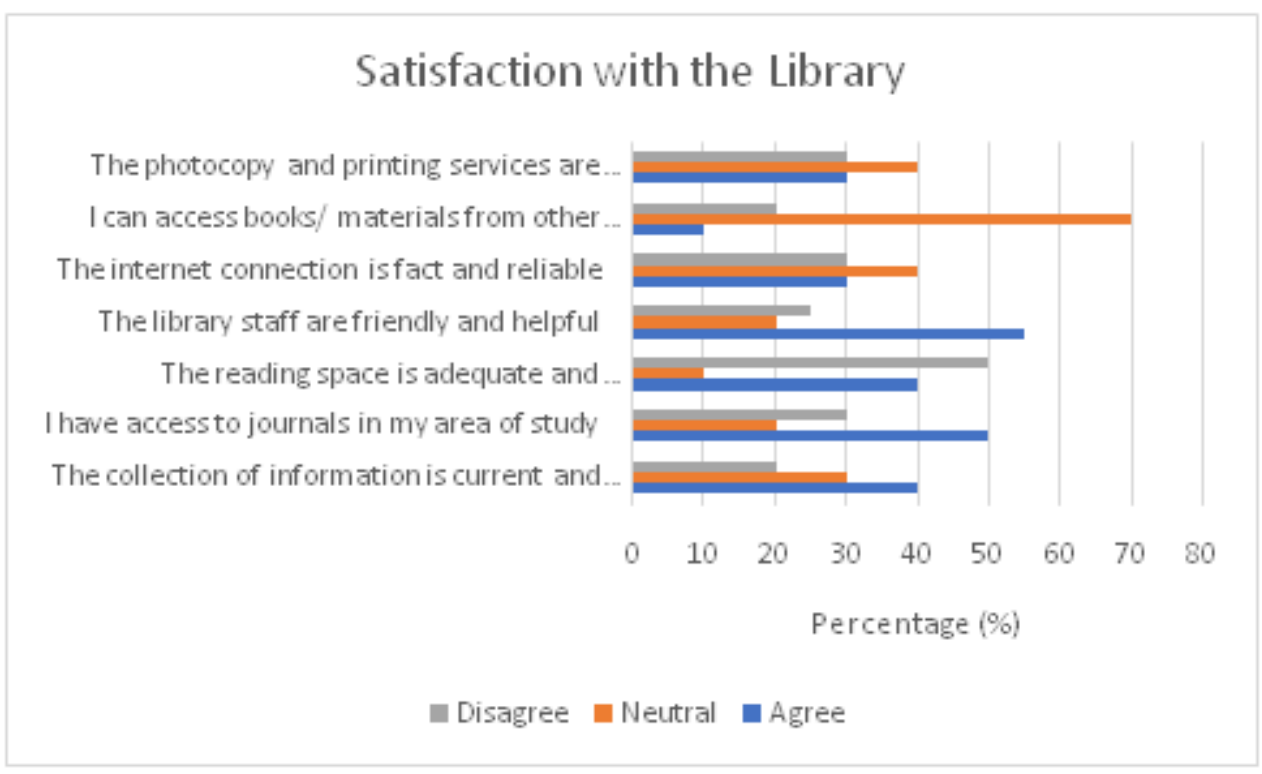

Figure7: Students' satisfaction with the library.

The students were satisfied with the collection of information at the library together with the services offered by library workers. The information was considered current and relevant to the different subject areas in the institution. Figure 7 shows that neutral responses were obtained regarding the quality and affordability of photocopy services, the speed and reliability of the internet connection and the accessibility of books and materials from other libraries. However, the reading space was inadequate for the needs of the students.

\subsection{Interview Findings from Library Staff}

The first theme highlighted from the interview was high library usage by students. The library workers realized that the rate of library use was high. However, it could still be improved. The second theme was the diversity of activities, which was responsible for the high library usage. The library offers a wide range of activities that attract students. For example, an internet connection, academic journals, books, inter-library borrowing facilities, study environment and photocopy and printing services. Therefore, students can visit the library to engage in any of these activities.

Themes related to barriers against optimal library use include regulations, cost, quality and awareness. The library has a set of rules and regulations that students are expected to adhere to. For instance, the production of student identification documents and maintaining silence throughout the building. Sometimes students forget to carry their identification documents with them, which prevents them 
from accessing the library thus failing to utilize its services. The main aspect related to cost is that printing and binding costs are slightly higher in the library than other business premises, which discourages students' use of these services. Quality issues included unstable internet connection and limited subscriptions to online journals or e-books. In contrast, awareness issues entail the lack of knowledge about certain library services that students can access, for example, the inter-university loan facility, which is highly underutilised.

As much as the rate of library usage was still high, it could still be increased by addressing the identified barriers. The main themes here were cost, quality and awareness. Examples of specific measures included subsidizing the cost of services such as printing and photocopy to encourage more students to use the services rather than using other business premises outside or within the university. Measures related to quality included stabilizing the internet connection and improving its speed to encourage student use, updating the library resources by getting recent editions of books and subscribing to more e-journals to improve the diversity of articles that students can access. Regarding awareness, some of the library services were underutilized because students were unaware that they existed. For example, few students know that it is possible to borrow books from other universities through the inter-university loan facility. The search for specific materials often ends once a student realizes that a specific book is inaccessible in the library.

Several studies have examined the attitudes of students on the use of library services with a special focus on electronic services (Dukic, Chiu \& Lo 2015; Wang \& Bai 2016; Jiao \& Onwuegbuzie 2017). However, this study did not concentrate on specific services but instead considered all library services. It was noted that about $25 \%$ of students visited the library to use the internet. Nevertheless, the actual activities that were done using the internet connection were not determined. The internet could be used to access informative material on websites such as YouTube, academic information available in online databases or general information. The internet could also be used to access email or social media sites such as Facebook, Twitter, Instagram and so on.

Assuming that internet use among the students who were examined involved accessing online databases, this rate was considerably low. Ukachi, Onuoha and Nwachukwu (2014) reported that the use of electronic information resources was low in institutions of higher learning due to negative attitudes towards electronic resources. The general notion was that searching for specific information was tedious and difficult. In a separate study by Henderson, Selwyn and Aston (2017), it was noted that the inability to locate relevant material during online searches left students confused and contributed to the development of negative attitudes towards online databases. Furthermore, slow internet connections sometimes discouraged students from using online resources in the library (Bagarukayo \& Kalema 2015). This sentiment was echoed during this study, further highlighting the importance of fast internet in the utilization of online databases.

Specific information needs are usually determined by the level of academic study (Jordan 2017). Overall, graduate students, especially at the doctoral level tend to use online databases more than undergraduate learners. At this level of study, there is a need to conduct thorough reviews of the literature on specific subjects, which necessitates online database use. This study focused mainly on undergraduate students. Therefore, it was not possible to obtain information about the attitudes of graduate students on the use of library resources.

\section{CONCLUSION AND RECOMMENDATIONS}

This study found that students at the learning institution had a positive attitude towards the use of the library facilities. They were satisfied with the quality of some resources, particularly books and online databases available to them. However, the library space was inadequate for their needs. There were neutral responses considering the ability to access materials from other libraries, which indicated the lack of awareness regarding the inter-library borrowing facility. As much as the rate of library use was high at $92 \%$, more students could be encouraged to use the library. Furthermore, there was room for improvement by increasing student satisfaction with all library services.

It was recommended that information literacy programmes should be conducted from time to time to remind students about the diversity of library services they can access. Arrangements should be made to expand the library space so that all students who are interested in conducting personal studies in the library can do so comfortably. The internet connection speed should be improved to ensure seamless 
experiences. Furthermore, the cost of certain library services such as printing and photocopy could be subsidised by the university to make them affordable to the population. Alternatively, the university could consider using market prices of printing and photocopy services. Students should also be encouraged to put their suggestions regarding what could be done to improve library services in the library's suggestion box. Future studies could look into the correlation between student attitudes and the frequency of library use and actual academic performance. The findings of such a study could serve as a motivation for increased library usage.

\section{REFERENCES}

[1] Artal, R, \& Rubenfeld, S 2017, 'Ethical issues in research', Best Practice \& Research Clinical Obstetrics \& Gynaecology, vol. 43, pp. 107-114.

[2] Bagarukayo, E \& Kalema, B 2015, 'Evaluation of e-learning usage in South African universities: a critical review,' International Journal of Education and Development using ICT, vol. 11, no. 2, pp. 168-183.

[3] Blackstone, A 2018, Principles of sociological inquiry: qualitative and quantitative methods, viewed 12 November 2019, <https://openlibrary-repo.ecampusontario.ca/xmlui/bitstream/handle/123456789/296/ Principles\%20of\%20Sociological\%20Inquiry.pdf? sequence=1\&isAllowed=y $>$.

[4] Brabazon, T 2016, The university of Google: education in the (post) information age, Routledge, New York, NY.

[5] Bryman, A 2016, Social research methods, Oxford University Press, Oxford, United Kingdom.

[6] Chen, Y H 2015, 'Testing the impact of an information literacy course: undergraduates' perceptions and use of the university libraries' web portal', Library \& Information Science Research, vol. 37, no. 3, pp. 263-274.

[7] Creswell, J W 2014, Research design: qualitative, quantitative and mixed methods approach, 4th edn, Sage Publications Inc, Los Angeles, CA.

[8] Delaney, G \& Bates, J 2015, 'Envisioning the academic library: a reflection on roles, relevancy and relationships', New Review of Academic Librarianship, vol. 21, no. 1, pp. 30-51.

[9] Dukic, Z, Chiu, D K \& Lo, P 2015, 'How useful are smartphones for learning? Perceptions and practices of library and information science students from Hong Kong and Japan', Library Hi Tech, vol.33, no. 4, pp. 545-561.

[10] Hammersley, M 2015, 'On ethical principles for social research', International Journal of Social Research Methodology, vol. 18, no. 4, pp. 433-449.

[11] Henderson, M, Selwyn, N \& Aston, R 2017, 'What works and why? Student perceptions of 'useful' digital technology in university teaching and learning', Studies in Higher Education, vol. 42, no. 8, pp. 15671579.

[12] Ibrahim, F L \& Sakiyo, J 2015, 'Aesthetics and utilization of university libraries in north east zone of Nigeria', Information Impact: Journal of Information and Knowledge Management, vol. 6, no. 3, pp. 1-20.

[13] Javadi, M \& Zarea, K 2016, 'Understanding thematic analysis and its pitfall', Journal of Client Care, vol. 1 , no. 1, pp. 33-39.

[14] Jiao, Q G, \& Onwuegbuzie, A J 2017, 'The impact of information technology on library anxiety: the role of computer attitudes', Information Technology and Libraries, vol. 23, no. 4, pp. 138-144.

[15] Jordan, P 2017, The academic library and its users, Routledge, New York, NY.

[16] Opsal, T, Wolgemuth, J, Cross, J, Kaanta, T, Dickmann, E, Colomer, S \& Erdil-Moody, Z 2016, “"There are no known benefits..." Considering the risk/benefit ratio of qualitative research', Qualitative Health Research, vol. 26, no. 8, pp. 1137-1150.

[17] Patten, M L 2016, Questionnaire research: a practical guide, Routledge, New York, NY.

[18] Pyrczak, F 2016, Making sense of statistics: a conceptual overview, Routledge, New York, NY.

[19] Rettig, J \& Hu, S 2016, 'College sport participation and student educational experiences and selected college outcomes', Journal of College Student Development, vol. 57, no. 4, pp. 428-446.

[20] Saunders, L 2015, 'Academic libraries' strategic plans: top trends and under-recognized areas', The Journal of Academic Librarianship, vol. 41, no. 3, pp. 285-291.

[21] Shapka, JD, Domene, JF, Khan, S \& Yang, LM 2016, 'Online versus in-person interviews with adolescents: an exploration of data equivalence', Computers in Human Behavior, vol. 58, pp. 361-367.

[22] Sharma, G 2017, 'Pros and cons of different sampling techniques', International Journal of Applied Research, vol. 3, no. 7, pp. 749-752.

[23] Taylor, SJ, Bogdan, R \& DeVault, M 2015, Introduction to qualitative research methods: a guidebook and resource, John Wiley \& Sons, Hoboken, NJ. 
[24] Ukachi, N B, Onuoha, U D \& Nwachukwu, V N 2014, 'Students' attitudes as a determining factor to electronic information resources use in university libraries in South-West, Nigeria', DESIDOC Journal of Library \& Information Technology, vol. 34, no. 4, pp. 333-341.

[25] Ulriksen, M S \& Dadalauri, N 2016, 'Single case studies and theory-testing: the knots and dots of the process-tracing method', International Journal of Social Research Methodology, vol. 19, no. 2, pp. 223239.

[26] Vadi, M G, Malkin, M R, Lenart, J, Stier, GR, Gatling, JW \& Applegate II, R L 2016, 'Comparison of web-based and face-to-face interviews for application to an anesthesiology training program: a pilot study', International Journal of Medical Education, vol. 7, pp. 102-108.

[27] Wang, S \& Bai, X 2016, 'University students awareness, usage and attitude towards e-books: experience from China', The Journal of Academic Librarianship, vol. 42, no. 3, pp. 247-258.

[28] Williams, G \& Pigeot, I 2017, 'Consent and confidentiality in the light of recent demands for data sharing', Biometrical Journal, vol. 59, no. 2, pp. 240-250.

\section{APPENDICES}

\section{Appendix A: Invitation to Participate in the Study}

Dear Prospective Participant

My name is ........., a student at ...... University. I am researching on the topic Attitude of Students Towards the Use of Library Facilities: A Case Study. The study is supervised by Prof. ...... of the department of ....... I am inviting you to take part in the study by completing an anonymous questionnaire or an interview schedule. The outcomes of the study will provide an understanding of students' attitudes on the library as an academic facility, which will contribute towards improving library services in the institution. The findings of the study may be published in a peer-reviewed journal.

Participation in this study is voluntary. You are free to opt out of the study at any time before submitting the questionnaire. Please complete the informed consent form to confirm your understanding of the project and agreement to participate. Also, feel free to contact the researcher for additional information or inquiries.

Thank you.

Student's Name

Phone number:

Email:

\section{Appendix B: Informed Consent Form}

I, (participant name), confirm that I have read and understood what the study entails and what is expected of me during participation. I am aware that my participation is voluntary and that my privacy and confidentiality will be upheld throughout the study. I, therefore, agree to take part in the study.

Participant Name.

Participant Signature.

Date.

\section{Appendix C: Students' Questionnaire}

SECTION A: Demographic Data

Please mark with $\boldsymbol{X}$ where appropriate

Gender

\begin{tabular}{|l|l|l|l|}
\hline Male & Female & \\
\hline
\end{tabular}

Age Group

\begin{tabular}{|l|l|}
\hline Age & \\
\hline $17-20$ & \\
\hline
\end{tabular}




\begin{tabular}{|l|l|}
\hline $21-25$ & \\
\hline $26-30$ & \\
\hline $31-35$ & \\
\hline 36 and above & \\
\hline
\end{tabular}

Year of Study

\begin{tabular}{|l|l|}
\hline 1 & \\
\hline 2 & \\
\hline 3 & \\
\hline 4 & \\
\hline 5 & \\
\hline
\end{tabular}

Do you use the library?

\begin{tabular}{|l|l|l|}
\hline Yes & No & \\
\hline
\end{tabular}

How often do you use the library in a month?

\begin{tabular}{|l|l|}
\hline I do not use the library & \\
\hline Once a month & \\
\hline Twice a month & \\
\hline On a weekly basis & \\
\hline Twice a week & \\
\hline
\end{tabular}

Which one of the following activities do you do most when you visit the library? (You can choose more than 1 answer)

\begin{tabular}{|l|l|}
\hline Meeting friends & \\
\hline Use the internet & \\
\hline Read newspapers & \\
\hline Borrow library books & \\
\hline Use library materials within the building & \\
\hline Read personal study notes & \\
\hline Use printing and photocopy services & \\
\hline Other reasons & \\
\hline
\end{tabular}

Section B: Students' perception of the library

Please mark with $\boldsymbol{X}$ where appropriate

Please indicate the extent to which you agree with the following statements on a scale of 1 to 5 (1= Strongly disagree, $2=$ Disagree, $3=$ Neutral, $4=$ Agree, $5=$ Strongly agree) .

\begin{tabular}{|c|c|c|c|c|c|}
\hline Statement & 1 & 2 & 3 & 4 & 5 \\
\hline The library provides study space and a conducive reading environment & & & & & \\
\hline The library provides access to useful study materials & & & & & \\
\hline The library provides adequate resources to help me stay updated with my area of study & & & & & \\
\hline The library helps me to cultivate a habit of self-study & & & & & \\
\hline
\end{tabular}

Please select statement(s) that best describe your perception(s) of the library.

I perceive the library as:

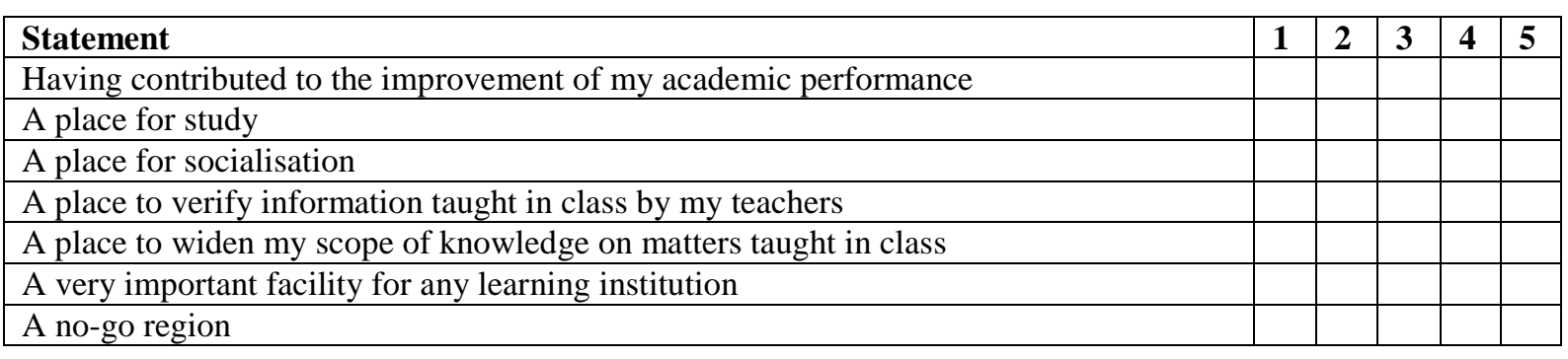

Please select statement(s) that best describe your satisfaction with the library.

\begin{tabular}{|c|c|c|c|c|c|}
\hline Statement & 1 & 2 & 3 & 4 & 5 \\
\hline The collection of information is current and pertinent to my study area & & & & & \\
\hline
\end{tabular}




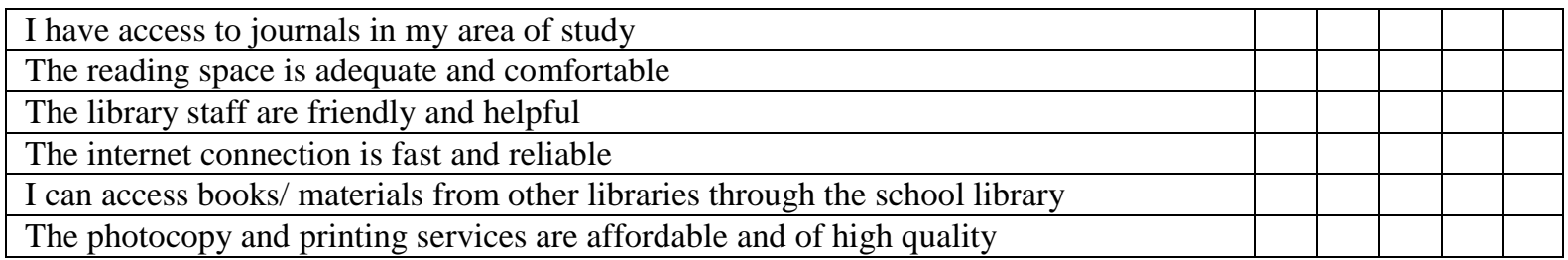

Thank you for your participation.

\section{Appendix D: Interview Schedule for Library Staff}

Questions

1. What role(s) do you think academic library play(s) in students' studies?

2. Please rate the students' library usage (high, moderate, low).

3. What are the facilitators of the effective use of library use by the students?

4. What are the barriers to the effective use of library use by the students?

5. What do you think can be done to improve the utilisation of the library by students?

Thank you for your participation.

Citation: Dr. Jamilah Alokluk. "Attitude of Students towards the Use of Library Facilities: A Case Study". International Journal of Humanities Social Sciences and Education (IJHSSE), vol. 7, no.1, 2020, pp. 24-36. doi: http://dx.doi.org/10.20431/2349-0381.0701003.

Copyright: () 2020 Authors. This is an open-access article distributed under the terms of the Creative Commons Attribution License, which permits unrestricted use, distribution, and reproduction in any medium, provided the original author and source are credited. 